\title{
Short- and Long-Term Memory Are Modulated by Multiple Isoforms of the Fragile X Mental Retardation Protein
}

\author{
Paromita Banerjee, ${ }^{1 \star}$ Brian P. Schoenfeld, ${ }^{2 \star}$ Aaron J. Bell, ${ }^{2}$ Catherine H. Choi, ${ }^{3}$ Michael P. Bradley, ${ }^{4}$ Paul Hinchey, ${ }^{2}$ \\ Maria Kollaros, ${ }^{2}$ Jae H. Park, ${ }^{5}$ Sean M. J. McBride, ${ }^{2}$ and Thomas C. Dockendorff ${ }^{5}$ \\ ${ }^{1}$ Department of Neurosciences, Lerner Research Institute, Cleveland Clinic, Cleveland, Ohio 44195, 2Department of Molecular Pharmacology, Albert \\ Einstein College of Medicine, Bronx, New York 10461, ${ }^{3}$ Department of Medicine, Lehigh Valley Health Network, Allentown, Pennsylvania 18105, ${ }^{4}$ Center for \\ Molecular Medicine and Genetics, Wayne State University School of Medicine, Detroit, Michigan 48201, and 5 Department of Biochemistry and Cellular and \\ Molecular Biology, University of Tennessee, Knoxville, Tennessee 37996
}

The diversity of protein isoforms arising from alternative splicing is thought to modulate fine-tuning of synaptic plasticity. Fragile $\mathrm{X}$ mental retardation protein (FMRP), a neuronal RNA binding protein, exists in isoforms as a result of alternative splicing, but the contribution of these isoforms to neural plasticity are not well understood. We show that two isoforms of Drosophila melanogaster FMRP (dFMR1) have differential roles in mediating neural development and behavior functions conferred by the $\mathrm{dfmr} 1$ gene. These isoforms differ in the presence of a protein interaction module that is related to prion domains and is functionally conserved between FMRPs. Expression of both isoforms is necessary for optimal performance in tests of short- and long-term memory of courtship training. The presence or absence of the protein interaction domain may govern the types of ribonucleoprotein (RNP) complexes dFMR1 assembles into, with different RNPs regulating gene expression in a manner necessary for establishing distinct phases of memory formation.

\section{Introduction}

Protein isoforms coded by alternatively spliced pre-mRNAs expand the functional repertoire of genes. The importance of this mechanism for developing protein diversity is illustrated by the finding that most multi-exon human genes are subject to alternative splicing (Pan et al., 2008). Alternative splicing is common in neural tissue, in which novel protein isoforms may function as on/off switches or graded modulators that fine-tune synaptic function (Lipscombe, 2005). The significance of alternative splicing to neurons is underscored by the variety of neurological diseases that result from its dysregulation (Licatalosi and Darnell, 2006).

Mutations in the fragile $\mathrm{X}$ mental retardation gene (FMR1) result in fragile $\mathrm{X}$ syndrome, a leading form of heritable mental retardation. The fragile $\mathrm{X}$ protein (FMRP) binds select RNA species, and the neural phenotypes of fragile $\mathrm{X}$ syndrome result in

Received Dec. 23, 2009; revised March 9, 2010; accepted April 2, 2010.

This work was funded by National Institutes of Health Grant GM068468 (T.C.D.) and by grants from the FRAXA Research Foundation (T.C.D., C.H.C., S.M.J.M.). We thank Neal Ferrick and Allison Terlizzi for technical assistance. Justin Fallon and Reed Wickner provided helpful discussions. Support from the faculty of the University of Tennessee Department of Biochemistry and Cellular and Molecular Biology and Dr. Thomas McDonald (Albert Einstein College of Medicine, New York, NY) was vital to this effort and is gratefully acknowledged. Mike O'Neil and the Research Computing Support group from the University of Tennessee Office of Information Technology provided advice on statistics. Antibodies were obtained from The University of lowa Developmental Studies Hybridoma Bank, and the laboratories of Susan Lindquist, Kausik Si, and Rodney Rothstein provided yeast strains and plasmids used for these studies.

*P.B. and B.P.S. contributed equally to this work.

Correspondence should be addressed to either of the following: Sean M. J. McBride, Department of Molecular Pharmacology, Albert Einstein College of Medicine, Bronx, NY 10461, E-mail:smcbride@aecom.yu.edu; or ThomasC. Dockendorff, Department of Biochemistry and Cellular and Molecular Biology, University of Tennessee, Knoxville, TN 37996, E-mail: tdockend@utk.edu.

DOI:10.1523/JNEUROSCI.6369-09.2010

Copyright $\odot 2010$ the authors $\quad 0270-6474 / 10 / 306782-11 \$ 15.00 / 0$ part from disruptions in trafficking of mRNA substrates through neuronal projections and translation regulation at the synapse (Bassell and Warren, 2008). Human FMRP (hFMRP) may exist in at least 20 isoforms that arise from alternative splicing (Ashley et al., 1993; Eichler et al., 1993; Verkerk et al., 1993), but the contributions of FMRP isoforms to neural plasticity are essentially unknown.

A Drosophila model to study FMRP function has been developed, with loss-of-function for $d f m r 1$ leading to neural phenotypes that have significant parallels with those of fragile $\mathrm{X}$ patients and mice (Gatto and Broadie, 2009). Like its mammalian counterparts, $d f m r 1$ pre-mRNA is subject to alternative splicing (FlyBase; http://flybase.bio.indiana.edu/). In this study, we use Drosophila genetics to delve into the role(s) of dFMR1 isoforms in neural development and behavioral plasticity and report on the role of a glutamine/asparagine $(\mathrm{Q} / \mathrm{N})$-rich protein interaction domain present in the $\mathrm{C}$ terminus of some dFMR1 isoforms through alternative splicing. The related C-terminal domain of human FMRP facilitates an interaction with kinesin and is needed for efficient FMRP-mediated dendritic RNA transport (Dictenberg et al., 2008). Deletion of the dFMR1 Q/N domain results in defects for a subset of neural development phenotypes associated with a null allele of $d f m r 1$, demonstrating that it is not essential for all dFMR1-regulated processes. The $\Delta \mathrm{Q} / \mathrm{N}$ mutants display an intermediate level of performance in tests of shortterm (STM) and long-term (LTM) memory when compared with wild-type and null alleles of $d f m r 1$. A decline in memory performance is observed with the $\Delta \mathrm{Q} / \mathrm{N}$ mutants during the transition from immediate recall to $1 \mathrm{~h}$ short-term memory of training. This decline parallels the protein synthesis requirement for maintaining metabotropic glutamate receptor-dependent long-term 
depression. The dFMR1 $\Delta \mathrm{Q} / \mathrm{N}$ protein may be defective in associating with ribonucleoprotein (RNP) complexes that promote RNA transport and/or regulate synaptic protein synthesis necessary for establishing memory. We find that expressing the dFMR1 $\mathrm{Q} / \mathrm{N}$ - isoform is also needed for optimal performance in shortand long-term memory of training. These observations may be explained by different isoforms of dFMR1 assembling into distinct RNP complexes that modulate patterns of protein synthesis required for establishing specific phases of memory. Our results indicate that unique biochemical properties associated with individual FMRP isoforms and the mechanisms that regulate their synthesis are necessary for normal cognition.

\section{Materials and Methods}

Fly stocks, transgene construction, and synthesis of transgenic stocks. Except when indicated, all fly stocks are derived from a $w^{1118}$ background. The $d f m r 1^{3}$ allele is a deletion that removes the entire open reading frame (Dockendorff et al., 2002; Banerjee et al., 2007). A 14 kb genomic rescue fragment spanning the $d f m r l$ locus has been described by Dockendorff et al. (2002). The terminal exon encoding the glutamine/asparagine domain was mutagenized as follows: PCR primers were devised to amplify a $2.0 \mathrm{~kb}$ fragment that resulted in a product that had NcoI and BspEI ends; these restriction sites are unique to the genomic rescue fragment. The amplification product was digested with these enzymes and ligated to the backbone of the rescue fragment that had been treated with the same enzymes. The substitution with the PCR product resulted in a construct in which 90 codons of $d f m r 1$ encompassing much of the $\mathrm{Q} / \mathrm{N}$ domain were removed. The PCR amplification product was produced with a proofreading polymerase (Vent polymerase; New England Biolabs) and was sequenced to ensure the absence of secondary mutations arising from base misincorporations. Substituting an NcoI/BspEI fragment from $d f m r 1$ genomic DNA with the corresponding fragment from $d f m r 1$ cDNA created the $d f m r 1^{L}$ allele, which does not produce the dFMR1 PB $(\mathrm{Q} / \mathrm{N}-)$ isoform. The mutant transgenes were introduced to $w^{1118}$ flies using standard transformation techniques. Resulting transgenic flies were then crossed into the $d f m r l^{3}$ background to produce fly stocks in which the mutant rescue fragment was the sole source of $d f m r 1$. Analysis of dFMR1 protein expression from the transgenes was measured by Western blotting, followed by quantification using ImageQuant (Molecular Dynamics) or NIH ImageJ software. Stocks expressing the $d f m r 1^{L}$ transgenes were crossed to each other to provide the reported doses of total dFMR1 protein. All $d f m r 1$ stocks were balanced with the TM6C Tb $\mathrm{Sb}$ chromosome.

Neuroanatomical analyses. Larval neuromuscular junction (NMJ) type I boutons were detected by staining third-instar larval fillets with antihorseradish peroxidase (Cappel) at a dilution of 1:200. Mushroom bodies were visualized by staining whole mounts of brains with anti-FasII at a 1:10 dilution (monoclonal antibody 1D4 obtained from the Developmental Studies Hybridoma Bank, University of Iowa, Iowa City, IA). Rabbit polyclonal antiserum against green fluorescent protein (GFP) was obtained from Invitrogen and used at a 1:200 dilution. Secondary antibodies conjugated to either HRP or fluorochrome were obtained from Jackson ImmunoResearch and used at a 1:200 dilution. Confocal images were collected on an Olympus FV500 microscope. Western blots were performed as described by Wan et al. (2000) using anti-dFMR1 antibody 5A11 at a 1:1000 dilution (ascites fluid) and anti- $\beta$-tubulin monoclonal antibody E7 (both from the Developmental Studies Hybridoma Bank, University of Iowa) at a 1:10,000 dilution (ascites fluid).

Analyses of dFMR1 Q/N domain function: transcription factor activity in Saccharomyces cerevisiae. Strain W303 (mat $\alpha$, leu2-3,112 trp1-1 ura3-1 ade2-1 his3-11,15) was provided by Rodney Rothstein (Columbia University, New York, NY) and used for the yeast assays. Transformations were done using lithium acetate as described by Gietz et al. (1992). The 122 aa of the dFMR1 Q/N-rich domain were fused to a constitutively active form of the glucocorticoid receptor transcription factor $\left(\mathrm{GR}^{526}\right)$ (Schena and Yamamoto, 1988) expressed via a glyceraldehyde-3phosphate dehydrogenase promoter. Fusion of $\mathrm{GR}^{526}$ to yeast prions has been used to monitor prion stability and inheritance (Li and Lindquist,
2000). The dFMR1 Q/N::GR ${ }^{526}$ plasmid was coexpressed with a plasmid harboring a $L a c Z$ gene with GR binding sites upstream. Yeast cells carrying these plasmids were plated to 5 -bromo-4-chloro-3-indolyl- $\beta$-Dgalactopyranoside (X-gal) media, and blue colonies were selected. These colonies were grown overnight in selective media, diluted, and plated again to X-gal media to monitor colony color. $\mathrm{GR}^{526}$ by itself was used as a control for native expression of LacZ. Plates were incubated for $3 \mathrm{~d}$ at $30^{\circ} \mathrm{C}$ and then photographed.

In vivo aggregation of GFP. GFP aggregation in Drosophila tissues was analyzed by driving expression of a dFMR1 Q/N::GFP fusion in thirdinstar larval muscle tissues with the myosin heavy chain GAL4 driver. The larval fillets were stained with rabbit anti-GFP primary antibody (1:200) and FITC-labeled anti-rabbit secondary antibody (1:200) to visualize GFP aggregates by confocal microscopy. Expression of native GFP was used as a control for any possible background aggregation.

Fly behavior: courtship and circadian behavior analyses. For courtship behavior testing, males of the appropriate genotypes were collected within $4 \mathrm{~h}$ of eclosion and kept in isolation before testing. Female targets were of the genotype $X X, y, f$ (attached $\mathrm{X}$ ) and collected as virgins for courtship testing. All flies were kept in $12 \mathrm{~h}$ light/dark cycles at $25^{\circ} \mathrm{C}$ and $50-75 \%$ relative humidity and were aged $4-9 \mathrm{~d}$ before analysis. For the naive courtship analysis, the male and female were transferred via aspiration to a mating chamber $20 \mathrm{~mm}$ in diameter and $5 \mathrm{~mm}$ deep. Males were given a $5 \mathrm{~min}$ recovery period before addition of the female target. Males were monitored for courtship activity that included orienting, following of the female, wing extension and vibration, tapping of female with his foreleg, and attempted copulation for a period of $10 \mathrm{~min}$, or until copulation occurred. The percentage of time the male spent courting the female was recorded, and this percentage is the courtship index (CI). Measurement of immediate recall was made by pairing a naive male with a nonreceptive female for a single $1 \mathrm{~h}$ training session and then placing him in a second chamber with a receptive female within 2 min of training. One hour short-term memory was assessed by taking a male that had been trained with a nonreceptive female for $1 \mathrm{~h}$ and placing him in isolation for $1 \mathrm{~h}$ before pairing with a receptive female. At least 17 animals were tested for each genotype during analyses of naive courtship, immediate recall, and short-term memory. The training paradigm for assessment of long-term memory is derived from McBride et al. (1999). Males were paired with a nonreceptive female for 7 continuous hours and then kept in isolation for $4 \mathrm{~d}$ before testing. Sham-trained males were treated identically, except for the exposure to the training female. The observers were blind to the genotypes of the animals for all courtship studies.

Circadian behavior was tested as described previously (Dockendorff et al., 2002). Flies were entrained to a $12 \mathrm{~h}$ light/dark cycle, placed into activity monitors (Trikinetics) maintained in light/dark cycles, and then placed under constant darkness. Locomotion activity was collected in 30 min bins. The percentage of flies judged to be rhythmic was assessed by Clocklab software (Actimetrics) as follows. Using a confidence level of 0.025 , batch analyses were performed for the genotypes tested, monitoring the locomotion activity in constant darkness over $7 \mathrm{~d}$. The difference between the power(1) and significance(1) values was calculated for each fly, and a value of $<10$ was the basis for judging an arrhythmic phenotype. Visual analyses of periodograms and actograms were also conducted to confirm the results. Strength of rhythmicity was calculated by the difference between the power(1) and significance(1) values for individual flies of each genotype tested.

Statistical analyses. Courtship indices were arcsin transformed and then analyzed by one-way ANOVA, followed by a Tukey-Kramer post hoc test. NMJ bouton counts and strength of circadian rhythmicity were analyzed by one-way ANOVA with a Tukey-Kramer post hoc test or by a Kruskal-Wallis test, followed by a Dunn's post hoc test. The analyses of courtship indices, NMJ bouton counts, and strength of circadian rhythmicity were conducted using InStat or Prism software from GraphPad Software. Comparisons of mushroom body axon midline crossings and percentage of animals judged rhythmic were made by Fisher's exact test or a $\chi^{2}$ test for homogeneity. 


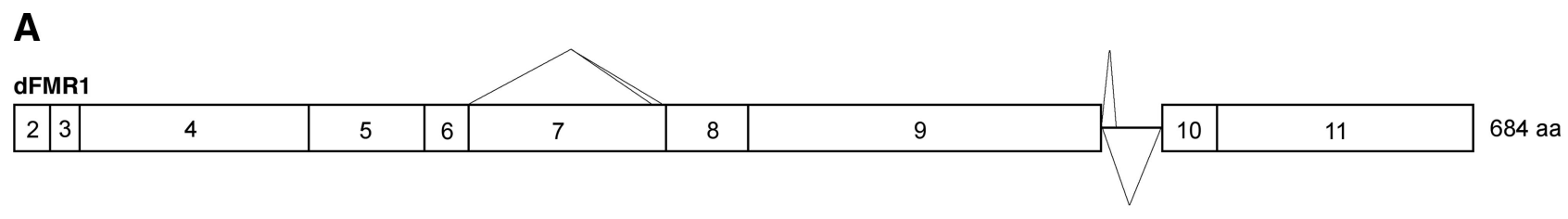

\begin{tabular}{|l|l|l|l||l|l|l|l|}
\hline Agenet 1 & Agenet 2 & Protein Interaction & KH1 & KH2 & & RGG & \\
\hline
\end{tabular}

hFMR1

\begin{tabular}{|l|l|l|l|l|l|l|l|l|l|l|l|l|l|l|l|l|l|}
\hline 1 & 2 & 3 & 4 & 5 & 6 & 7 & 8 & 9 & 10 & 11 & 12 & 13 & 14 & 15 & 16 & 17 \\
6
\end{tabular}

B

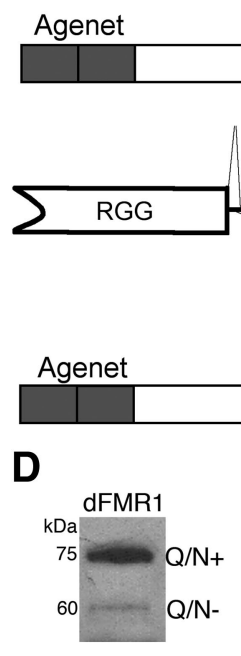

Q/N- 529 aa

$\uparrow$ mitorentabea

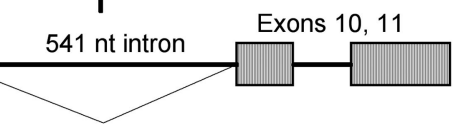

$\checkmark$ Intron spliced

$\mathrm{KH} 1 \mathrm{KH} 2 \quad \mathrm{RGG}$
C

GTGAGTTCCGCGAATCATGATGCCAATTAACCAATTAGTTCAATCAATTT ATTTCGCGCGCTCACACAAGATACAAATTGAATACTCGATCCGATTCCCT CTCCСCTAAATATGGACATCATGTGGGGTCAAGAATACGAAAATTTGTAC AGCAAGTTTATTAGTTATTAAACAGTATAAAGTATTACATTAAGGACTGT TTCATAAAATCCCTATAATTATAGCATTCTGAATAAAATAAATGAAATTA TCTTGGTTTATTTTGTGTAAAGTATGATAATAAACTTTTCAAAAGTAAAA CATTATACATTATTGAATCTTAACTTTCGCTTTCATTGCCAACAATATAA TATATAAAATAGAAACACTGACCTGGGCTTTGTATTTAAATAAATATCAA AATATATATTTTTTCATTTAATTGAAGTGCGCAGGGGCACAGACAATGAA TTTTTGCTGATGAAGTTATTTCCTTTTTATCGTCATCTGTAATCTCTGCT AGTATACTATGATAACTTATCCATTATCCTTTTCTCCACAG

$\mathrm{Q} / \mathrm{N}+684$ aa

E

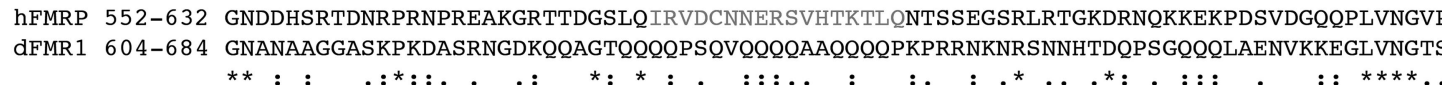

hFXR1 541-621 ISRAESQSRQRNLPRETLAKNKKEMAKDVIEEHGPSEKAINGPTSASGDDISKLQRT--PGEEKINTLKEENTQEAAVLNGVS dFMR1 604-684 --GNANAAGGASKPKDASRNGDKQQAGTQQQQPSQVQQQQAAQQQQPKPRRNKNRSNNHTDQPSGQQQLAENVKKEGLVNGTS

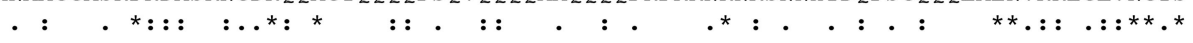

hFXR2 593-673 NRGNRTDGSISGDRQPVTVADYISRAESQSRQRPPLERTKPSEDSLSG--QKGDSVSKLPKGPSENGELSAPLELGSMVNGVS dFMR1 604-684 --GNANAAGGASKPKDASRNGDKQQAGTQQQQPSQVQQQQAAQQQQPKPRRNKNRSNNHTDQPSGQQQLAENVKKEGLVNGTS **... ... . : . .:* :*.:* . : : : : : : . . : : : . : .** : :*: : : ..****

Figure 1. Alternative splicing produces FMRP isoforms in mammals and Drosophila. $A$, Schematic of alternative splicing patterns in the human and D. melanogaster FMR1 genes that lead to diversity in C-terminal peptide domains. In hFMRP, the presence of a nuclear export sequence is dependent on inclusion of exon 14 in the mature transcript, and choice of the $3^{\prime}$ acceptor site in exon 15 determines the presence of a serine residue that is a phosphorylation substrate. An alternative 3 ' acceptor site is present in exon 17 . Skipping of exon 14 creates a +1 frame shift (Ashley et al., 1993), resulting in FMRP isoforms with novel C-terminal peptides. A bar over exons 13-17 of hFMRP denotes a region that interacts with kinesin light chain (Dictenberg et al., 2008). $\boldsymbol{B}$, In $D$. melanogaster, a $541 \mathrm{nt}$ intron that separates exons 9 and 10 of $\mathrm{dfmr} 1$ is alternatively spliced to produce the $\mathrm{dFMR} 1 \mathrm{Q} / \mathrm{N}+$ and $\mathrm{Q} / \mathrm{N}-$ isoforms. C, Sequence of the $541 \mathrm{nt}$ intron between exons 9 and 10 of $d f m r 1$. The retained 3' segment of this intron contains several consensus hexanucleotide sequences (AAUAA) that recruit the cleavage and polyadenylation machinery. The $\mathrm{Q} / \mathrm{N}-\mathrm{is}$ form (designated PB in FlyBase; http://flybase.bio.indiana.edu/) lacks a glutamine/asparagine-rich peptide encoded by exon 11. D, The 529 aa Q/N - isoform of dFMR1 is detected via Western blot of protein extract from heads and constitutes a modest fraction of total dFMR1 protein. $\boldsymbol{E}$, C-terminal peptides of human FMR/FXR and dFMR1 are related. A ClustalW alignment reveals that an 81 aa peptide, encoded by exons 16 and 17 of human FMR1, shares $38 \%$ identity/similarity with the terminal 81 residues of dFMR1. Amino acids of hFMRP depicted in gray denote residues that arise from use of an alternate splice acceptor site in exon 17. ClustalW alignment of the terminal 81 residues of dFMR1 with human FXR1 and FXR2 shows 33 and $43 \%$ identity/similarity between the peptides. A Blosum scoring matrix, opening and end gap penalties of 10 , and extending and separation gap penalties of 0.05 , which are the default values for the ClustalW program, were used for the analyses.

\section{Results}

\section{Alternative splicing produces isoforms of dFMR1 protein}

Early studies of human FMR1 gene and transcript structure revealed the presence of multiple transcript isoforms resulting from exon skipping or the use of alternative splice sites during FMR1 pre-mRNA processing (Ashley et al., 1993; Eichler et al., 1993; Verkerk et al., 1993). The synthesis of at least 20 human FMR1 mRNAs is possible, but several of these transcripts comprise only a minor fraction of total FMR1 mRNA (Ashley et al., 1993; Verkerk et al., 1993; Xie et al., 2009). Most alternative splicing of FMR1 pre-mRNA occurs in regions of the transcript that code for the C-terminal domain of the protein (Fig. 1A). FMRP isoforms can lack or have alterations in functional domains such as the second KH domain, a nuclear export sequence, and a major phosphorylation site (Sittler et al., 1996; Didiot et al., 2008). In addition to removing a nuclear export sequence in FMRP, skipping of exon 14 in human FMR1 pre-mRNA leads to a +1 frame shift that results in proteins with novel C-terminal peptides (Ashley et al., 1993; Sittler et al., 1996). Altered biochemical properties are ascribed to some FMRP isoforms (Sittler et al., 1996; Xie et al., 2009), and the switch between phosphorylation states is seemingly critical for synaptic plasticity (Narayanan et al., 2007; Pfeiffer and Huber, 2007). However, the contribution of most FMRP isoforms to neural function remains essentially uncharacterized.

Transcript isoforms of the D. melanogaster fragile $\mathrm{X}$ gene $(d f m r 1)$ are present based on analyses of cDNAs (Fig. 1A) 
A

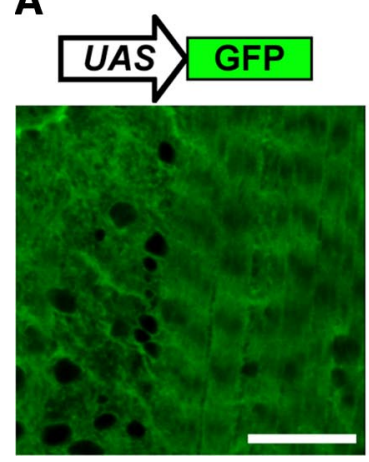

B

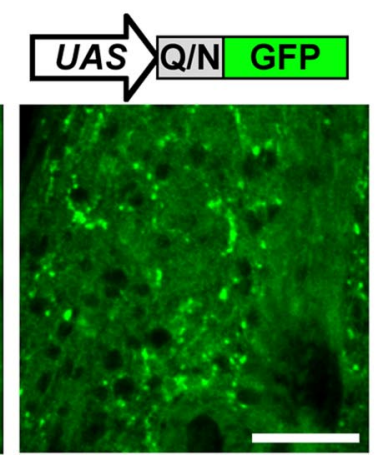

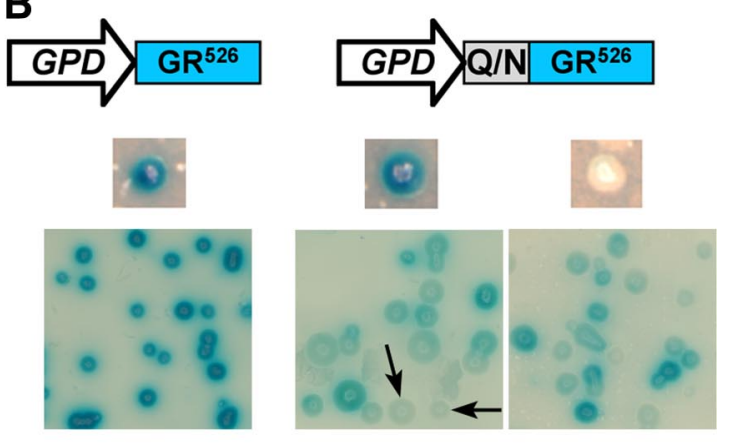

Figure 2. The C-terminal Q/N domain of dFMR1 has protein interaction properties. $A$, Fusion of codons specifying the dFMR1 Q/N domain to GFP results in aggregation of GFP signal, although none is observed with native GFP. Scale bars, $10 \mu \mathrm{m}$. B , The dFMR1 Q/N domain does not confer a metastable state of activity to a reporter protein. Fusion of the dFMR1 Q/N domain to a constitutively active glucocorticoid receptor $\left(G R^{526}\right)$ transcription factor results in a high level of fluctuation in LacZ expression, resulting in colonies that vary in the degree of X-gal hydrolysis. Cultures derived either blue or white colonies give a mix of blue and white when plated to X-gal media. Arrowheads point to white colonies derived from blue colony parental material. GPD, Glyceraldehyde-3phosphate dehydrogenase.

(FlyBase; http://flybase.bio.indiana.edu/). Like human FMR1, $d f m r 1$ pre-mRNA is subject to alternative splicing that results in $\mathrm{dFMR} 1$ isoforms with alterations in the second $\mathrm{KH}$ domain and composition of the C-terminal peptide. The C-terminal truncation associated with the PB isoform (FlyBase; http://flybase.bio. indiana.edu/) of dFMR1 is derived from an alternative splicing event in which much of a $541 \mathrm{nt}$ intron is retained (Fig. $1 \mathrm{~B}$ ). The retained intron serves as a source for codons that specify a C-terminal peptide with the sequence DTN, a termination codon, and canonical hexanucleotide sequences (AAUAAA) that facilitate $3^{\prime}$ end formation of the transcript (Fig. 1C). The PB isoform (referred to as Q/N - through the text) is 529 aa, and a protein corresponding to its predicted mass can be detected on Western blots of tissue extracts (Fig. 1D). As is observed with several hFMRP isoforms, the $\mathrm{Q} / \mathrm{N}$ - isoform constitutes a minor fraction of total dFMR1 protein.

\section{The C-terminal peptides of hFMRP and dFMR1 are related and function as protein interaction modules}

Although the presence of RNA-binding and protein interaction domains in the N-terminal amino acids of FMRP and the FXR paralogs have been noted for some time, a role for C-terminal amino acids had been less clear. Recent studies of the hFMRP C-terminal peptide strongly indicate that it has protein interaction capacity, as judged by yeast two-hybrid screening using the C-terminal peptide as a bait (Menon et al., 2004) and the finding that a C-terminal truncation of hFMRP inhibits its interaction with kinesin (Dictenberg et al., 2008). A comparison of the C-terminal 81 aa encoded by exons 16-17 of FMR1 and the terminal 81 aa of dFMR1 shows significant conservation, with 31 of 81 residues $(38 \%)$ being identical or similar (Fig. 1E). Two 3' splice acceptor sites are present in exon 17 of human FMR1 premRNA and dictate the presence or absence of 17 codons within the exon (Eichler et al., 1993) (Fig. 1E). In addition to FMR1, mammalian genomes encode the paralogous FXR1 and FXR2 genes (Siomi et al., 1995; Zhang et al., 1995). The C-terminal peptide of dFMR1 was compared with corresponding sequences from FXR1 and FXR2, and the ClustalW alignment reveals 33 and 43\% amino acid identity/similarity, respectively (Fig. $1 E$ ).

Examination of C-terminal amino acids that are coded by the terminal $3^{\prime}$ exon of $d f m r 1$ reveal that this 122 aa peptide is unusually enriched in glutamine and asparagine $(\mathrm{Q} / \mathrm{N})$ residues $(36 \% \mathrm{Q} / \mathrm{N})$ (Fig. $1 E$ ). Protein domains enriched in $\mathrm{Q} / \mathrm{N}$ residues are common in eukaryotic proteomes (Michelitsch and Weissman, 2000; Harrison and Gerstein, 2003) and, when studied, act as modules that facilitate interactions with both homologous and heterologous proteins (Decker et al., 2007, Guo et al., 2007; Shewmaker et al., 2007; Kim et al., 2008). To test whether the dFMR1 Q/N domain has protein interaction properties, genes encoding GFP or a dFMR1 Q/N::GFP fusion were cloned behind an upstream activating sequence, and their expression was driven by myosin heavy chain-GAL4. Examination of larval muscles expressing either of the GFP isoforms shows that only the dFMR1 $\mathrm{Q} / \mathrm{N}:$ :GFP fusion exhibits aggregation of GFP antigen in these tissues (Fig. 2A), showing that the dFMR1 Q/N domain can facilitate protein interactions in vivo. A protein interaction function is likely conserved between the C-terminal peptides of hFMRP and dFMR1.

The series of short glutamine repeats in the dFMR1 C-terminal peptide sequence resembles those present in prionforming domains from fungi. Aggregation of Saccharomyces cerevisiae Sup 35 proteins to propagate a prion state is dependent on protein interactions between their Q/N-rich domains (for review, see Shorter and Lindquist, 2005; Wickner et al., 2007). Adoption of a prion-like state has been proposed as a means to maintain regulators of long-term memory in a self-sustaining active form (Si et al., 2003, 2010). Two independent algorithms devised to identify $\mathrm{Q} / \mathrm{N}$-rich domains with prion-forming potential both uncover dFMR1 (Michelitsch and Weissman, 2000; Harrison and Gerstein, 2003). To test whether the Q/N domain of dFMR1 has such properties, we fused it to a reporter protein used to detect and monitor prion-like activity. The Sup35 NM and Aplysia cytoplasmic polyadenylation element binding (CPEB) $\mathrm{Q} / \mathrm{N}$ domains confer a metastable state of activity when fused to an otherwise constitutively active GR transcription factor $\left(\mathrm{GR}^{526}\right.$ ) (Schena and Yamamoto, 1988; Li and Lindquist, 2000; Si et al., 2003). In this assay, yeast colonies plated on X-gal media only rarely switch between functional (blue colony) and nonfunctional (white colony) states of the $\mathrm{GR}^{526}$ transcription factor. When the 122 codons of the exon encompassing the dFMR1 Q/N domain are fused to $\mathrm{GR}^{526}$, we observe a high level of switching between active and inactive states of the $\mathrm{GR}^{526}$ transcription factor, as judged by scoring blue and white colonies that appear on X-gal plates (Fig. 2 B). This degree of instability contrasts with the high level of stability observed with the prion-forming Sup35 NM domain and the Q/N-rich domain of Aplysia CPEB protein ( $\mathrm{Li}$ 
and Lindquist, 2000; Si et al., 2003) and indicates that the dFMR1 Q/N domain may not have true prion-forming properties. Studies have shown that $<20 \%$ of proteins that are candidates for prion formation in yeast actually adopt such a state (Michelitsch and Weissman, 2000; Sondheimer and Lindquist, 2000; Alberti et al., 2009). Nonetheless, a protein interaction capacity for the dFMR1 Q/N domain may facilitate interactions with RNP complexes that regulate neural function.

\section{Mutation analysis of the dFMR1 \\ $\mathrm{Q} / \mathrm{N}$ domain}

A $14 \mathrm{~kb}$ genomic rescue fragment encompassing the $d f m r 1$ locus rescues phenotypes associated with the $d f m r 1^{3}$ deletion null mutation (Dockendorff et al., 2002). We used this rescue fragment to create a 270 bp deletion derivative that removed most of the codons specifying $\mathrm{Q}$ or $\mathrm{N}$ from the $3^{\prime}$ exon (Fig. 3A,B) (see Materials and Methods). The mutant rescue fragment was introduced by $P$ element transformation, and two independent transgene insertions were subsequently analyzed. The mutant rescue fragments were crossed into a $d f m r r^{3}$ null background to generate stocks in which the mutant transgene is the sole source of dFMR1 protein. The truncated proteins are stable in a steady state as judged by Western blotting (Fig. $3 C)$. Quantification of signals from Western blots shows that a single copy of the transgene results in a level of dFMR1 protein that is either equivalent to that observed in a $w^{1118}$ control animal $(\Delta \mathrm{Q} / \mathrm{N} 8)$ or at $\sim 1.8$-fold overexpression $(\Delta \mathrm{Q} / \mathrm{N} 1 \mathrm{~B})$ (Fig. $3 C)$. Whole-mount staining of adult brains with anti-dFMR1 antibody shows that mutant animals have a spatial expression pattern of $\mathrm{dFMR} 1$ in the CNS that is indiscernible from the pattern observed in brains of wild-type animals (Fig. 3D,E).

\section{Differential requirements for the $\mathrm{Q} / \mathrm{N}$ domain in development and behavior}

Deletion null alleles of $d f m r 1$ elicit pleiotropic phenotypes that include defects in embryogenesis, neuronal development, and behaviors of larvae and adults (Zhang et al., 2001; Dockendorff et al., 2002; Morales et al., 2002; Lee et al., 2003; Michel et al., 2004; Deshpande et al., 2006; Monzo et al., 2006). We then set out to discern the phenotypic consequences of deleting the dFMR1 $\mathrm{Q} / \mathrm{N}$ domain. Several possibilities exist for the effects of the $\mathrm{Q} / \mathrm{N}$ deletion on dFMR1 function. As a likely protein interaction platform, the $\mathrm{Q} / \mathrm{N}$ domain could be essential for all dFMR1 functions, and animals with the $\Delta Q / N$ allele would then exhibit phenotypes indistinguishable from those with a null allele. Conversely, the association of AFMR1 with other protein complexes might involve both the $\mathrm{Q} / \mathrm{N}$ domain and a second protein interaction platform common to FMRPs (Fig. 1A). The function of the other protein interaction domain might be enough to compensate for the loss of the $\mathrm{Q} / \mathrm{N}$ domain and thus result in no change from the wild-type phenotypes. Finally, it is possible that the dFMR1 Q/N domain facilitates interactions with protein complexes that mediate select dFMR1 processes. If this were the case, variation in the relative strength of phenotypes resulting from the $\Delta Q / N$ allele would be predicted.
The development phenotypes of embryos produced by $d f m r 1$ mutant females include defects in cellularization and cleavage furrow formation that are ascribed to misregulation of cytoskeletal dynamics. The breakdown of these embryonic development processes results in hatch rates of embryos from $d f m r 1$ mutant females being approximately half that of embryos from wild-type mothers (Monzo et al., 2006). To assess the effects of the Q/N deletion on embryonic development, we mated wild-type males with wild-type females, those homozygous for the $d f m r 1^{3}$ null allele, and females expressing the transgene alleles of $d f m r 1$ in which the region coding for the $\mathrm{Q} / \mathrm{N}$ domain is deleted and measured the hatch rate of eggs. The results presented in Figure $4 A$ show that both transgenic lines expressing the mutant dFMR1 protein provide a significant level of rescue of embryonic hatch rates over that observed with embryos from females homozygous for the $d f m r 1^{3}$ deletion null allele.

In wild-type flies, the $\beta$-lobe axons of mushroom bodies infrequently cross the midline of the central brain. However, flies homozygous for null alleles of $d f m r 1$ display a midline-crossing defect in these axons with a high level of penetrance (Michel et al., 2004; Banerjee et al., 2007). We examined the brains of 2-d-old adults harboring wild-type, null, or $\mathrm{Q} / \mathrm{N}$ domain deletion alleles of $d f m r 1$ for this phenotype. Both transgenes expressing the dFMR $1 \Delta \mathrm{Q} / \mathrm{N}$ domain provide significant rescue of the phenotype observed with the null allele control (Fig. $4 B$ ). These results, along with those observed with the embryonic hatch rate, show that functions and properties conferred by the $\mathrm{Q} / \mathrm{N}$ domain are not essential for the ability of dFMR1 to execute at least a subset of its normal activities. 
A

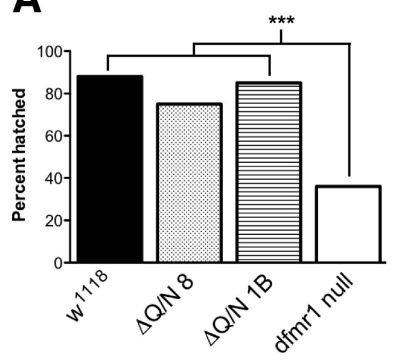

B

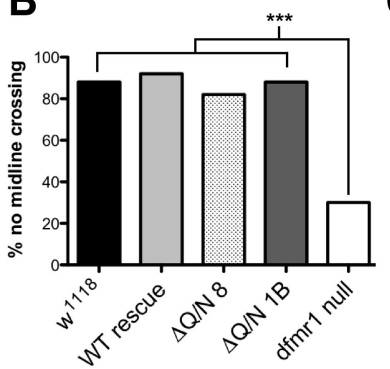

C

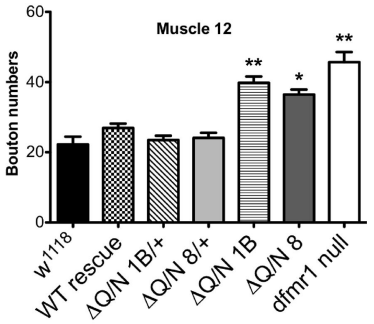

D

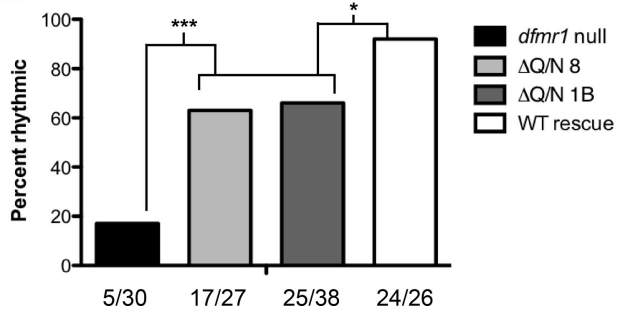

E

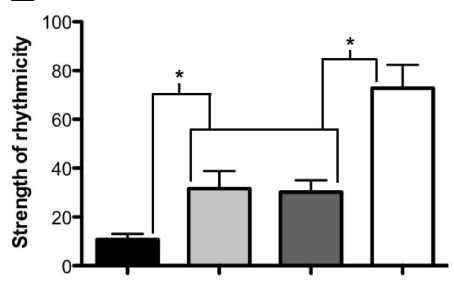

Figure 4. Developmental and circadian locomotion phenotype of $\Delta \mathrm{Q} / \mathrm{N}$ flies. $\boldsymbol{A}$, Hatch rates of eggs deposited by females expressing $\mathrm{dFMR} 1 \Delta \mathrm{Q} / \mathrm{N}$ protein are greater than those of $\mathrm{dfmr} 1 \mathrm{null}$ females and do not differ significantly from those of wild-type (WT) females. $n>290$ for all genotypes tested; and $p \leq 0.0001, \chi^{2}$ test for homogeneity. $B$, The $\Delta Q / N$ flies do not exhibit a frequency of midline crossing of mushroom body $\beta$-lobe axons that differs from wild type. $n>30$ for all genotypes examined; $p \leq$ $0.001, \chi^{2}$ test for homogeneity. $C$, An excess of neuromuscular junction boutons are present in larvae expressing the $\Delta Q / N$ allele as the sole source of dFMR1 protein compared with those expressing a wild-type allele of dfmr1. ${ }^{* *} p \leq 0.01$; ${ }^{* * *} p \leq 0.001$, ANOVA. $\boldsymbol{D}, \boldsymbol{E}$, The $\Delta Q / \mathrm{N}$ flies have a partial loss-of-function phenotype in rhythmic circadian locomotion activity. $\boldsymbol{D}$, The percentage of $\Delta \mathrm{Q} / \mathrm{N}$ flies judged to be rhythmic [based on a power(1)/significance(1) difference $>10$ ] is lower than wild type and higher than that of flies with a deletion null allele of $d f m r 1\left({ }^{*} p \leq 0.05 ;{ }^{* * *} p \leq 0.001\right.$, Fisher's exact test). $\boldsymbol{E}$, The strength of circadian locomotion rhythms in flies harboring the $\Delta Q / \mathrm{N}$ allele is intermediate to those with wild-type or null alleles of $d f m r 1\left(^{*} p \leq 0.05\right.$, ANOVA). power(1) and significance(1) values were derived from Clocklab software (Actimetrics).

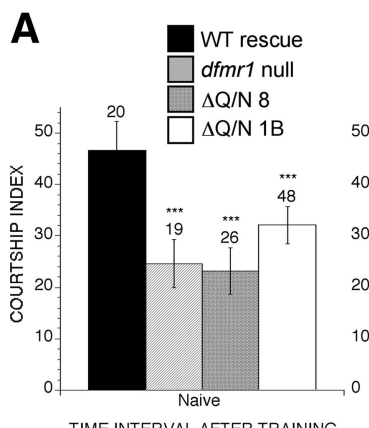

TIME INTERVAL AFTER TRAINING

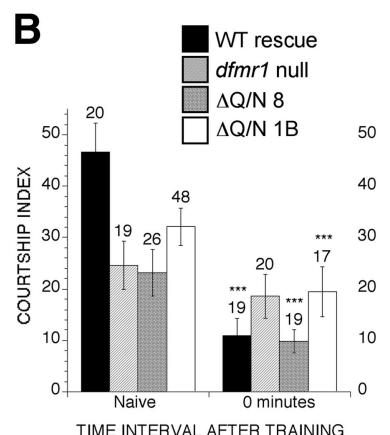

TIME INTERVAL AFTER TRAINING

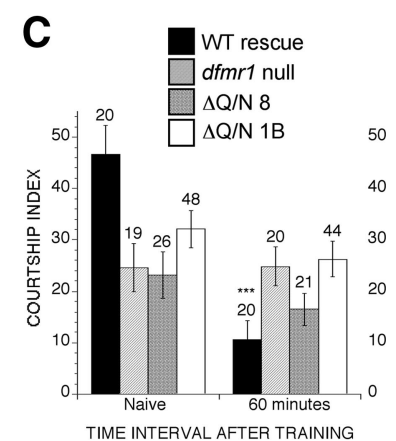

TIME INTERVAL AFTER TRAINING

Figure 5. Social behavior and short-term memory phenotypes of $d f m r 1 \Delta Q / N$ mutants. $A$, The $\Delta Q / N$ mutants have a significant decrease in naive courtship activity compared with flies with a wild-type (WT) dfmr1 allele. B, C, dfmr1 $1 \mathrm{Q} / \mathrm{N}$ mutants exhibit immediate recall ( $0-2$ min after training) but not $1 \mathrm{~h}$ short-term memory of conditioned courtship training. Flies with wild-type, null, or $\Delta Q / N$ alleles of $d f m r 1$ were paired with a nonreceptive female for $1 \mathrm{~h}$ (training) and subsequently paired with a receptive virgin female at the above times for testing memory of training. The significant reduction in courtship index seen at $0-2 \mathrm{~min}$ after training compared with the naive controls with wild-type and $\Delta \mathrm{Q} / \mathrm{N}$ flies demonstrates memory of the training. In contrast, the $1 \mathrm{~h}$ posttraining courtship indices of $\Delta Q / N$ mutants rise to a level similar to the naive control, whereas the wild-type flies retain suppressed courtship activity. ${ }^{* * *} p \leq 0.001$, ANOVA.

are presented in Figure $4 C$ and show that the loss of the $\mathrm{Q} / \mathrm{N}$ domain results in a significant increase in bouton numbers when compared with larvae that are expressing a wild-type allele of $d f m r 1$. Larvae expressing both wild-type and $\Delta \mathrm{Q} / \mathrm{N}$ alleles of $d f m r 1$ had numbers of boutons like those of wild-type controls, showing the $\Delta Q / N$ alleles are recessive. Similar phenotypes were observed with muscles 4 and 6/7 (supplemental Fig. 1, available at www.jneurosci.org as supplemental material). That the $\Delta Q / N$ allele elicits bouton numbers that resemble those observed with the null allele (Fig. $4 C$ ) indicates that the $\mathrm{Q} / \mathrm{N}$ domain is a significant factor for dFMR1 function in this process of synaptic development.

A null mutation of $d f m r 1$ results in loss of rhythmic circadian locomotion activity that likely occurs via misregulation of one or more clock-controlled output genes (Dockendorff et al., 2002). We thus tested the $\mathrm{Q} / \mathrm{N}$ deletion transgenic stocks for their ability to maintain rhythmic locomotion activity in constant darkness. The results in Figure $4 D$ show that $\sim 60 \%$ of the animals from the $\Delta \mathrm{Q} / \mathrm{N}$ transgenic lines retain rhythmic locomotion in constant darkness compared with $\sim 20 \%$ of null mutants and $>90 \%$ of $d f m r 1^{3}$ homozygotes that express a wild-type allele of $d f m r 1$. Strength of rhythmicity for the $\Delta \mathrm{Q} / \mathrm{N}$ flies, as measured by the difference in power(1) and significance(1) values, is intermediate between those with wildtype or null alleles (Fig. $4 E$ ). As was seen with the NMJ bouton numbers, the $\Delta \mathrm{Q} / \mathrm{N}$ mutation behaves as a recessive allele (supplemental Fig. 2, available at www. jneurosci.org as supplemental material). Two possibilities could explain the partial penetrance and expressivity of the circadian locomotion phenotypes displayed by animals with the $\Delta Q / N$ allele. First, both $\mathrm{Q} / \mathrm{N}+$ and $\mathrm{Q} / \mathrm{N}-$ isoforms could contribute to the ability of the $d$ fmrl locus to control outputs from the circadian clock. Alternatively, the $\mathrm{Q} / \mathrm{N}$ domain enhances, but is not essential for, protein interactions that facilitate regulation of clock outputs by dFMR1.
Larvae homozygous for a null allele of $d f m r 1$ have elevated numbers of neuromuscular junction boutons, which are the swellings associated with synapse formation. The increase in boutons is attributable in part to excessive branching from the axons that innervate the larval muscles (Zhang et al., 2001). Using larvae expressing a wild-type rescue fragment in an otherwise $d f m r 1$ null background, larvae homozygous for a null allele of $d f m r 1$, and larvae expressing dFMR1 with a deletion of the Q/N domain, we examined muscle 12 from larval segment A4 for numbers of type 1 boutons. The results from these experiments

\section{Social behavior during courtship is impaired by the $\mathrm{Q} / \mathrm{N}$ deletion}

Courtship in Drosophila involves a series of stereotyped behaviors between the courting male and the female mate (for review, see Greenspan and Ferveur, 2000). Although conduct of these behaviors requires the function of several sensory modalities, their ethological relevance has made analysis of Drosophila courtship a common method to study genes that control behaviors and processes of learning and memory (for review, see Mehren et al., 2004). When placed with a receptive virgin female, naive males 
will initiate courtship behaviors that include orienting to the female, following and tapping the female with his foreleg, extension and vibration of a wing, licking the female with his proboscis, and attempts at copulation. The percentage of time engaged in these behaviors over a defined period is referred to as the courtship index (CI).

Males homozygous for a null mutation of $d f m r 1$ have a reduction in naive courtship activity compared with wild-type flies (Dockendorff et al., 2002), indicating that dFMR1 protein is needed for establishment and/or function of neural pathways needed for efficient courtship behavior. However, $d f m r 1$ mutant males can achieve copulation, indicating that their reduced courtship index is not simply the consequence of a total deficit in sensory detection or processing of courtship cues. We tested the dFMR1 $\Delta \mathrm{Q} / \mathrm{N}$ transgenic stocks for naive courtship behavior. Removal of the $\mathrm{Q} / \mathrm{N}$ domain results in naive courtship levels that resemble those of the null allele control (Fig. 5A). The $\mathrm{Q} / \mathrm{N}$ domain of dFMR1 is thus necessary for development and/or function of neural circuitry that facilitates naive courtship behavior.

\section{The dFMR1 Q/N domain contributes toward establishment of short-term memory}

Conditioned courtship is a paradigm for memory in which unreceptive Drosophila females present visual, behavioral, and pheromone-based cues toward a courting male that results in a reduction of his courtship activity. Moreover, the inhibition of the male's courtship activity carries over to receptive females and thus represents a form of associative memory. Depending on the training regimen with a nonreceptive female, this memory can be maintained for periods of a few hours (short-term memory) to long-term memory that lasts several days (Siegel and Hall, 1979; McBride et al., 1999). Previous studies have established that, like wild-type males, the CI of $d f m r 1$ null mutants declines during training, demonstrating that the mutant is able to detect and respond to the negative courtship cues displayed by the female (McBride et al., 2005). Flies homozygous for a null allele of $d f m r 1$ are deficient in both immediate recall (0-2 min after training) and $1 \mathrm{~h}$ STM of conditioned courtship training (McBride et al., 2005).

The necessity for the dFMR1 Q/N domain on immediate recall and STM was tested with conditioned courtship. Males with wildtype, null, or $\Delta \mathrm{Q} / \mathrm{N}$ alleles of $d f m r 1$ were paired with unreceptive females for a single $1 \mathrm{~h}$ training session. Trained males were removed from the courtship chamber and placed with a receptive female (immediate recall) or left in isolation for $1 \mathrm{~h}$ and then paired with a receptive female to assess STM of the training. A comparison of the naive $\mathrm{CI}$ and the posttraining $\mathrm{CI}$ shows that flies expressing the $\Delta \mathrm{Q} / \mathrm{N}$ protein have a significant decrease in courtship at the immediate recall stage, indicating that they have retained memory of the training (Fig. $5 B$ ). In contrast, there is not a significant difference between the naive $\mathrm{CI}$ of $\Delta \mathrm{Q} / \mathrm{N}$ flies and the $\mathrm{CI}$ measured $1 \mathrm{~h}$ after
B
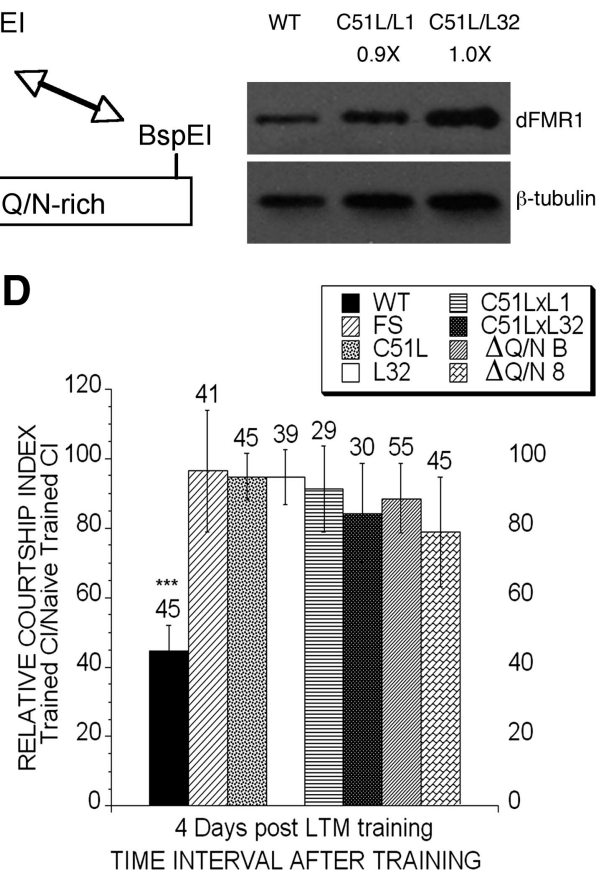

100

80

60

40

20

TIME INTERVAL AFTER TRAINING

Figure 6. Flies unable to produce the $\mathrm{dFMR} 1 \mathrm{Q} / \mathrm{N}$ - isoform have $1 \mathrm{~h}$ STM of courtship training but are deficient in $4 \mathrm{~d}$ long-term memory of training. $\boldsymbol{A}$, Schematic of the $d f m r 1^{L}$ allele. A cDNA clone was used to replace $d f m r 1$ genomic DNA in which the

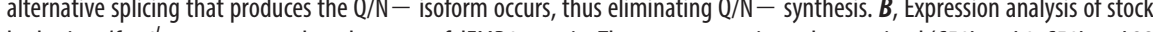
normatized to that of $\beta$-tubulin. $C$, Flies expressing the $d f m r{ }^{L}$ allele have naive courtship levels that equal or exceed those of independent insertion lines were tested (C51L, L32, and L1). ${ }^{* * *} p \leq 0.001$, ANOVA. D, Flies expressing either the dfmr ${ }^{L}$ or $\Delta Q / N$ lines provide approximately a haploid dose of dFMR1 protein, $d f m r 1^{L}$ stocks were crossed to each other to increase the protein dose to that of a diploid (C51L $\times \mathrm{L} 1, \mathrm{C} 51 \mathrm{~L} \times \mathrm{L} 32) .{ }^{* * *} p \leq 0.001$, ANOVA. FS, Frame-shift null allele.

training (Fig. 5C), whereas courtship levels of wild-type controls remain suppressed.

Relative memory performance between genotypes was assessed through use of a memory index (for review, see Kamyshev et al., 1999). We performed these analyses for the immediate recall and $1 \mathrm{~h}$ STM, comparing wild-type, $\Delta \mathrm{Q} / \mathrm{N}$, and $d f m r 1$ null flies. Although flies expressing the $\Delta \mathrm{Q} / \mathrm{N}$ protein are judged to have immediate recall of training, the memory performance of these animals is intermediate to the wild-type and null alleles (supplemental Fig. 3, available at www.jneurosci.org as supplemental material). Although the memory index in wild-type flies does not decline from immediate recall to $1 \mathrm{~h}$ after training, the memory index for $\Delta \mathrm{Q} / \mathrm{N}$ mutants and nulls declines during this interval. At $1 \mathrm{~h}$ after training, the $\Delta \mathrm{Q} / \mathrm{N}$ mutants still retain a memory index intermediate to those of wild-type and $d f m r 1$ null flies (supplemental Fig. 3, available at www.jneurosci.org as supplemental material). Together, these studies show that the $\mathrm{Q} / \mathrm{N}$ domain is important for establishment of short-term memory.

\section{Production of the dFMR1 Q/N isoform is necessary for long-term memory of training}

To assess needs for the $\mathrm{Q} / \mathrm{N}$ - isoform of AFMR1, we generated a derivative of the $d f m r 1$ genomic rescue fragment in which DNA 


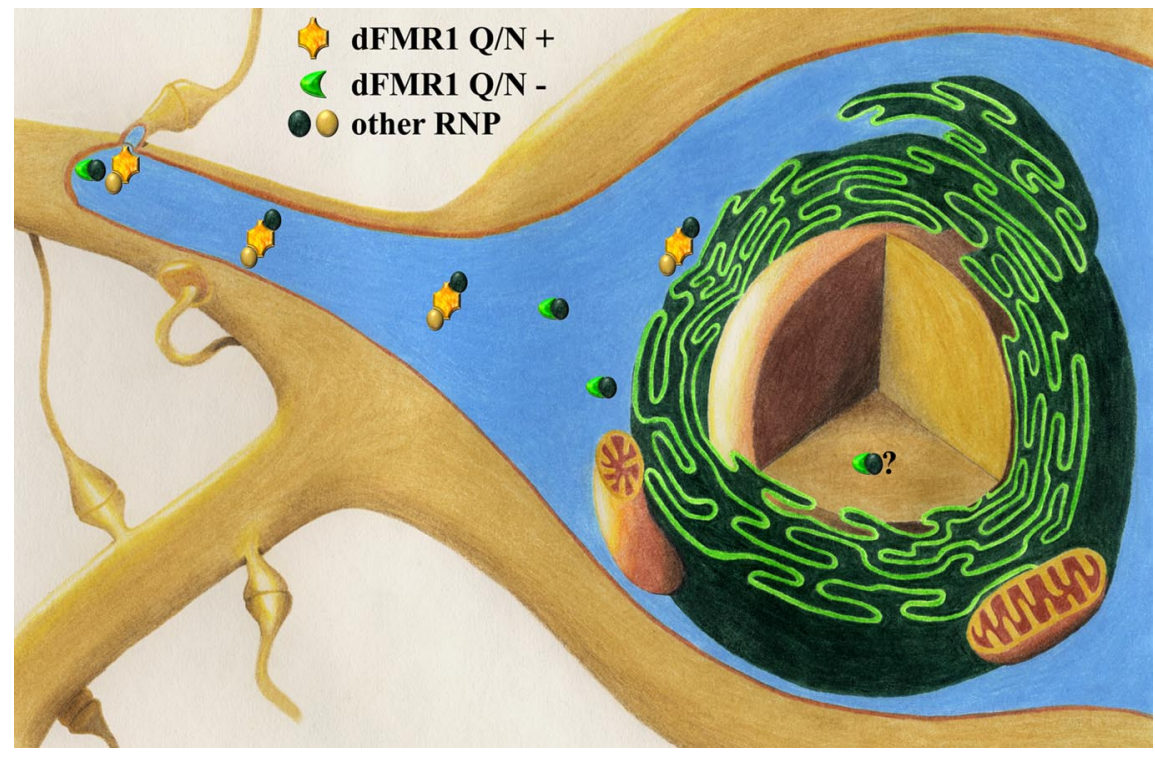

Figure 7. A model for functions of $\mathrm{dFMR} 1 \mathrm{Q} / \mathrm{N}+$ and $\mathrm{Q} / \mathrm{N}-$ isoforms in neurons based on results from this study and other published observations on FMRP function. The deficit in $1 \mathrm{~h}$ STM in $\Delta Q / \mathrm{N}$ flies parallels the requirement for protein synthesis in mGluR-induced hippocampal LTD (Huber et al., 2000, 2002). The C-terminal peptides of human FMRP facilitate an interaction with kinesin (Dictenberg et al., 2008) and are related to the C-terminal peptide of dFMR1 (Fig. 1E). The dFMR1 Q/N domain may then allow for interactions with RNP complexes that promote dendritic RNA trafficking and/or regulation of local translation of mRNA species that are critical for early stages of memory formation. Production of the dFMR1 Q/N - isoform is critical for $4 \mathrm{~d}$ LTM of courtship training. The $\mathrm{Q} / \mathrm{N}-$ isoform could contribute to regulated expression of genes that further consolidate memory of training. This might occur through translation regulation mechanisms within dendrites or spines. Alternatively, de novo transcription is required for certain forms of LTM. FMRP is detected in the nucleus, and roles for FMRP in chromatin regulation, RNA processing, and nucleocytoplasmic transport of RNA have been reported or proposed (Deshpande et al., 2006; Lai et al., 2006; Didiot et al., 2008). Disruption of isoform-specific roles for any of these steps in nuclear gene expression may contribute to the observed deficit in LTM.

encompassing the alternatively spliced intron was substituted with $d f m r 1 \mathrm{cDNA}$, resulting in an allele $\left(d f m r 1^{L}\right)$ that is unable to produce the Q/N- isoform (Fig. 6A,B). We analyzed flies expressing this construct as the sole source of dFMR1 protein for the same neural development and behavior phenotypes used to study the $\mathrm{Q} / \mathrm{N}$ domain deletions. The developmental phenotypes of NMJ bouton overgrowth and midline crossing by mushroom body axons were absent in such animals, and no defects in rhythmic circadian locomotion were observed (supplemental Fig. 4, available at www. jneurosci.org as supplemental material). We then tested flies for courtship behavior and memory of conditioned courtship training. Flies unable to produce the dFMR $1 \mathrm{Q} / \mathrm{N}-$ isoform have a naive courtship level that is similar to that of wild-type controls and exhibit $1 \mathrm{~h} \mathrm{STM}$ of courtship training (Fig. 6C). We then tested these flies for LTM of courtship training using a $7 \mathrm{~h}$ uninterrupted training regimen described by McBride et al. (1999). Both $d f m r 1^{L}$ alleles and allele combinations tested reveal a deficit in $4 \mathrm{~d}$ long-term memory of courtship training (Fig. 6D), showing that the function of the $\mathrm{dFMR} 1 \mathrm{Q} / \mathrm{N}$ - isoform and the alternative splicing pathway that results in its production have a critical role in establishment of long-term memory.

\section{Discussion}

The FMR1 pre-mRNA from mammals and D. melanogaster is alternatively spliced to produce FMRP isoforms, but the necessity for these isoforms in promoting neural plasticity is essentially uncharacterized. The Drosophila fragile X model facilitates a molecular genetics approach to probe the contribution of FMRP isoforms to neural function. We have explored the importance of dFMR1 isoforms that differ in the presence of a protein interac- tion domain related to those found in prions and find that their expression is necessary for proper modulation of memory establishment pathways.

\section{Common functions for C-terminal peptides of FMR/FXR proteins}

The genome of $D$. melanogaster encodes one FMR/FXR protein, whereas vertebrate genomes encode three. FMR/FXR proteins are highly conserved in their $\mathrm{N}$-terminal RNA binding domains but are more diverged in the $\mathrm{C}$-terminal region (for alignment, see Wan et al., 2000). It was initially presumed that both redundant and distinct functions were possible among vertebrate FMR/FXR proteins, and recent studies now support this hypothesis. The $\mathrm{KH} 2$ domains from the mouse and fly FMR/FXR proteins recognize an RNA substrate with a kissing complex structure, but high-affinity recognition of a select G-quadruplex RNA substrate is unique to mammalian FMRP (Darnell et al., 2009). The highly related CYFIP1 and CYFIP2 proteins have differential binding profiles with FMR/FXR proteins (Schenck et al., 2001). Behavior and neurophysiology studies of FMR1 FXR2 double knock-outs shows that, although FMRP and FXR2 have overlapping function in controlling mouse circadian locomotion (Zhang et al., 2008), distinct synaptic plasticity phenotypes exist in the single mutants (Zhang et al., 2009). Muscle and cardiac development phenotypes arise from morpholino knockdown of FXR1 expression in zebrafish, and the function and/or low expression of FMRP or FXR2 in these tissues fails to compensate (Van't Padge et al., 2009). It is thus likely that expression pattern, RNA binding, and protein interaction partners all factor into whether FMR/FXR proteins can or cannot provide compensatory function. The C-terminal peptides of hFMRP and dFMR1 are implicated as protein interaction modules (Menon et al., 2004; Dictenberg et al., 2008; this study), and the moderate degree of similarity between C-terminal peptides of FMR/FXR proteins (Fig. 1E) suggest a related function. Divergence between C-terminal sequences of vertebrate FMRP, FXR1, and FXR2 may facilitate diversification and specialization of their function via the ability to interact with distinct subsets of proteins.

Protein domains with elevated levels of $\mathrm{Q} / \mathrm{N}$ residues are quite common in eukaryotic proteomes (Michelitsch and Weissman, 2000; Harrison and Gerstein, 2003), and, in fungi, a subset of Q/N-rich proteins form prions (Shorter and Lindquist, 2005; Alberti et al., 2009). Adoption of a prion-like state has been suggested as a means by which regulators of neural plasticity can be stabilized to maintain long-term memory (Si et al., 2003, 2010; Bailey et al., 2004). Although our results indicate that the dFMR1 $\mathrm{Q} / \mathrm{N}$ domain does not behave as a prion, it is important to note that most $\mathrm{Q} / \mathrm{N}$ domains do not form prions (Michelitsch and Weissman, 2000; Sondheimer and Lindquist, 2000; Alberti et al., 2009). Nonetheless, Q/N domains have properties relevant to the roles that FMRP plays in dendrites and the postsynaptic compartment. High levels of $\mathrm{Q} / \mathrm{N}$ residues promote protein-protein in- 
teraction through the hydrogen bonding that can occur via the side chains of these amino acids (Perutz et al., 1994) and mediate both homologous and heterologous protein interactions (Decker et al., 2007; Guo et al., 2007; Shewmaker et al., 2007; Kim et al., 2008). The $\mathrm{Q} / \mathrm{N}$ domain of yeast Lsm4p is needed for assembly and aggregation of RNA-regulating P bodies (Decker et al., 2007). Dendritic RNA transport and regulated protein synthesis are necessary for metabotropic glutamate receptor (mGluR)-induced long-term depression and other forms of synaptic plasticity and memory (Huber et al., 2000; Costa-Mattioli et al., 2009). The memory deficits seen with the $\Delta \mathrm{Q} / \mathrm{N}$ mutants are consistent with the $\mathrm{Q} / \mathrm{N}$ domain facilitating interactions with RNP complexes that mediate RNA transport and translation regulation.

It is interesting to speculate that the ancestral FMR/FXR protein had a $\mathrm{Q} / \mathrm{N}$ domain, because the high degree of conservation in terminal amino acids of dFMR1 and mammalian FMR/FXR proteins (LVNGVS consensus) (Fig. $1 E$ ) suggests that the exons encoding these peptides share a common ancestor. Duplication of the ancestral FMR/FXR gene would allow divergent evolution of codons that specify C-terminal peptides. A similar situation is possible with the RNA-binding Orb/CPEB protein family. Although the Aplysia CPEB and D. melanogaster Orb2 proteins have a $\mathrm{Q} / \mathrm{N}$-rich domain, the four mammalian CPEB paralogs have comparatively modest levels of Q/N residues ( $\mathrm{Si}$ et al., 2003; Theis et al., 2003; Keleman et al., 2007; Richter, 2007).

\section{Multiple isoforms of dFMR1 contribute to establishment of memory}

Although the dFMR1 Q/N+ isoform is important for acquisition of short- and long-term memory, it is by itself insufficient for development of long-term memory. Given the need for dFMR1 $\mathrm{Q} / \mathrm{N}+$ and $\mathrm{Q} / \mathrm{N}$ - isoforms in short- and long-term memory, a question then is how these isoforms contribute to changes in neurons and synapses undergoing the transitions necessary to form and maintain LTM. The deficits in both short- and longterm memory observed with fragile $\mathrm{X}$ models arise at least in part from misregulated protein synthesis (Dölen et al., 2007; Bolduc et al., 2008; Liao et al., 2008). Thus, a possible explanation for the roles of dFMR1 $\mathrm{Q} / \mathrm{N}+$ and $\mathrm{Q} / \mathrm{N}-$ isoforms to formation of short- and long-term memory is that there are differential patterns of gene expression that the two isoforms regulate. Multiple protein interaction domains are present in FMRP (Fig. $1 A$ ), and absence of the $\mathrm{Q} / \mathrm{N}$ domain may allow assembly of the $\mathrm{Q} / \mathrm{N}-$ isoform into functionally distinct subsets of RNP complexes that facilitate gene regulation events needed for LTM. The RNAbinding CPEB protein Orb2 from $D$. melanogaster has a glutaminerich domain essential for LTM but not STM of conditioned courtship training, and it is suggested to function as an interaction domain for factors that modulate Orb2 activity (Keleman et al., 2007). Both transcription and local translation can provide the de novo protein synthesis required for longer-lasting forms of plasticity (for review, see Kelleher et al., 2004; Hoeffer and Klann, 2007; Barrett and Wood, 2008; Costa-Mattioli et al., 2009). The activity of Aplysia CPEB protein is needed up to $48 \mathrm{~h}$ after serotonin stimulation to maintain long-term facilitation (Miniaci et al., 2008), and regulated translation of ATF-4 represses CREBmediated long-term potentiation and LTM (Costa-Mattioli et al., 2007). Although the role for FMRP in postsynaptic translation regulation is widely accepted, it may also regulate gene expression within the nucleus. Isoforms of hFMRP lacking exon 14 have a predominant nuclear localization (Sittler et al., 1996), and roles for FMRP in chromatin regulation, pre-mRNA splicing, and nucleocytoplasmic trafficking of mRNA are reported or proposed
(Deshpande et al., 2006; Lai et al., 2006; Didiot et al., 2008). Figure 7 depicts possibilities for dFMR1-regulated pathways of gene expression that contribute to formation and consolidation of memory.

The need for specific FMRP isoforms in neural plasticity makes it important to consider the mechanisms that dictate alternative splice patterns of FMR1 pre-mRNAs. The nature of processes that control spatial and/or temporal expression patterns of FMRP isoforms are not known, but human FMRP binds to a G-quartet-forming segment of its transcript, in which it is then proposed to autoregulate FMR1 pre-mRNA splicing (Didiot et al., 2008). Synaptic activity controls alternative splicing of the pre-mRNA encoding the NR1 subunit of the NMDA receptor (Mu et al., 2003), and it is interesting to note that components of the splicing machinery are detected in dendrites (Glanzer et al., 2005). FMR1 mRNAs are present in synaptoneurosomes and translated in response to neurotransmitter stimulation (Weiler et al., 1997). Given the proposed function of FMRP as a regulator of alternative splicing (Didiot et al., 2008), the possibility that synaptic activity could control a dendrite-localized splicing function for FMRP and/or FMR1 transcripts is intriguing. Changes in the profile of FMRP isoforms could also occur via selective protein turnover, and at least some of the FMRP pool is subject to ubiquitination and degradation within minutes after chemical stimulation of hippocampal slices (Hou et al., 2006). Future studies will reveal whether regulated synthesis and degradation of select FMRP isoforms arises from synaptic stimulation.

\section{Concluding comments}

FMRP is implicated in regulating the expression of synaptic plasticity genes such as Arc/Arg3.1, calcium/calmodulin-dependent kinase II $\alpha$, and Map1b (for review, see Bassell and Warren, 2008). The role for FMRP in both short- and long-term memory of training is consistent with the possibility that it is a component of a synaptic tag and/or contributes to its synthesis (Martin and Kosik, 2002), and the protein interaction capacity of the FMRP C-terminal peptide may facilitate its capture by tagged synapses. It will be of interest to find whether there are FMRP-regulated genes whose products promote a distinct phase of memory establishment. The availability of animal stocks that express a specific isoform of FMRP will be useful as biochemical tools to capture FMRP-containing RNP complexes. Such complexes might harbor RNA substrates that are unique to a particular FMRP-RNP, and identification of these RNAs will help elucidate the patterns of gene expression that contribute toward consolidation of memory.

\section{References}

Alberti S, Halfmann R, King O, Kapila A, Lindquist S (2009) A systematic survey identifies prions and illuminates sequence features of prionogenic proteins. Cell 137:146-158.

Ashley CT, Sutcliffe JS, Kunst CB, Leiner HA, Eichler EE, Nelson DL, Warren ST (1993) Human and murine FMR-1: alternative splicing and translational initiation downstream of the CGG-repeat. Nat Genet 4:244-251.

Bailey CH, Kandel ER, Si K (2004) The persistence of long-term memory: a molecular approach to self-sustaining changes in learning-induced synaptic growth. Neuron 44:49-57.

Banerjee P, Nayar S, Hebbar S, Fox CF, Jacobs MC, Park JH, Fernandes JJ, Dockendorff TC (2007) Substitution of critical isoleucines in the KH domains of Drosophila fragile X protein results in partial loss-of-function phenotypes. Genetics 175:1241-1250.

Barrett RM, Wood MA (2008) Beyond transcription factors: the role of chromatin modifying enzymes in regulating transcription required for memory. Learn Mem 15:460-467.

Bassell GJ, Warren ST (2008) Fragile X syndrome: loss of local mRNA regulation alters synaptic development and function. Neuron 60:201-214. 
Bolduc FV, Bell K, Cox H, Broadie KS, Tully T (2008) Excess protein synthesis in Drosophila fragile X mutants impairs long-term memory. Nat Neurosci 11:1143-1145.

Costa-Mattioli M, Gobert D, Stern E, Gamache K, Colina R, Cuello C, Sossin W, Kaufman R, Pelletier J, Rosenblum K, Krnjević K, Lacaille JC, Nader K, Sonenberg N (2007) eIF2alpha phosphorylation bidirectionally regulates the switch from short- to long-term synaptic plasticity and memory. Cell 129:195-206.

Costa-Mattioli M, Sossin WS, Klann E, Sonenberg N (2009) Translational control of long-lasting synaptic plasticity and memory. Neuron 61:10-26.

Darnell JC, Fraser CE, Mostovetsky O, Darnell RB (2009) Discrimination of common and unique RNA-binding activities among fragile $\mathrm{X}$ mental retardation protein paralogs. Hum Mol Genet 18:3164-3177.

Decker CJ, Teixeira D, Parker R (2007) Edc3p and a glutamine/asparaginerich domain of Lsm4p function in processing body assembly in Saccharomyces cerevisiae. J Cell Biol 179:437-449.

Deshpande G, Calhoun G, Schedl P (2006) The Drosophila fragile X protein dFMR1 is required during early embryogenesis for pole cell formation and rapid nuclear division cycles. Genetics 174:1287-1298

Dictenberg JB, Swanger SA, Antar LN, Singer RH, Bassell GJ (2008) A direct role for FMRP in activity-dependent dendritic mRNA transport links filopodial-spine morphogenesis to fragile $\mathrm{X}$ syndrome. Dev Cell 14:926-939.

Didiot MC, Tian Z, Schaeffer C, Subramanian M, Mandel JL, Moine H (2008) The G-quartet containing FMRP binding site in FMR1 mRNA is a potent exonic splicing enhancer. Nucleic Acids Res 36:4902-4912.

Dockendorff TC, Su HS, McBride SM, Yang Z, Choi CH, Siwicki KK, Sehgal A, Jongens TA (2002) Drosophila lacking dfmrl activity show defects in circadian output and fail to maintain courtship interest. Neuron 34:973-984.

Dölen G, Osterweil E, Rao BS, Smith GB, Auerbach BD, Chattarji S, Bear MF (2007) Correction of fragile X syndrome in mice. Neuron 56:955-962.

Eichler EE, Richards S, Gibbs RA, Nelson DL (1993) Fine structure of the human FMR1 gene. Hum Mol Genet 2:1147-1153.

Gatto CL, Broadie K (2009) The fragile X mental retardation protein in circadian rhythmicity and memory consolidation. Mol Neurobiol 39:107-129.

Gietz D, St Jean A, Woods RA, Schiestl RH (1992) Improved method for high efficiency transformation of intact yeast cells. Nucleic Acids Res 20:1425.

Glanzer J, Miyashiro KY, Sul JY, Barrett L, Belt B, Haydon P, Eberwine J (2005) RNA splicing capability of live neuronal dendrites. Proc Natl Acad Sci U S A 102:16859-16864.

Greenspan RJ, Ferveur JF (2000) Courtship in Drosophila. Annu Rev Genet 34:205-232.

Guo L, Han A, Bates DL, Cao J, Chen L (2007) Crystal structure of a conserved N-terminal domain of histone deacetylase 4 reveals functional insights into glutamine-rich domains. Proc Natl Acad Sci USA 104:4297-4302.

Harrison PM, Gerstein M (2003) A method to assess compositional bias in biological sequences and its application to prion-like glutamine/ asparagine-rich domains in eukaryotic proteomes. Genome Biol 4:R40.

Hoeffer CA, Klann E (2007) Switching gears: translational mastery of transcription during memory formation. Neuron 54:186-189.

Hou L, Antion MD, Hu D, Spencer CM, Paylor R, Klann E (2006) Dynamic translational and proteasomal regulation of fragile $\mathrm{X}$ mental retardation protein controls mGluR-dependent long-term depression. Neuron 51:441-454.

Huber KM, Kayser MS, Bear MF (2000) Role for rapid dendritic protein synthesis in hippocampal mGluR-dependent long-term depression. Science 288:1254-1257.

Huber KM, Gallagher SM, Warren ST, Bear MF (2002) Altered synaptic plasticity in a mouse model of fragile $\mathrm{X}$ mental retardation. Proc Natl Acad Sci U S A 99:7746-7750.

Kamyshev NG, Iliadi KG, Bragina JV (1999) Drosophila conditioned courtship: two ways of testing memory. Learn Mem 6:1-20.

Keleman K, Krüttner S, Alenius M, Dickson BJ (2007) Function of the Drosophila CPEB protein Orb2 in long-term courtship memory. Nat Neurosci 10:1587-1593.

Kelleher RJ 3rd, Govindarajan A, Tonegawa S (2004) Translational regulatory mechanisms in persistent forms of synaptic plasticity. Neuron 44:59-73.

Kim DH, Kim GS, Yun CH, Lee YC (2008) Functional conservation of the glutamine-rich domains of yeast Gal11 and human SRC-1 in the transactivation of glucocorticoid receptor Tau 1 in Saccharomyces cerevisiae. Mol Cell Biol 28:913-925.

Lai D, Sakkas D, Huang Y (2006) The fragile X mental retardation protein interacts with a distinct mRNA nuclear export factor NXF2. RNA 12:1446-1449.

Lee A, Li W, Xu K, Bogert BA, Su K, Gao FB (2003) Control of dendritic development by the Drosophila fragile X-related gene involves the small GTPase Rac1. Development 130:5543-5552.

Li L, Lindquist S (2000) Creating a protein-based element of inheritance. Science 287:661-664.

Liao L, Park SK, Xu T, Vanderklish P, Yates JR 3rd (2008) Quantitative proteomic analysis of primary neurons reveals diverse changes in synaptic protein content in fmrl knockout mice. Proc Natl Acad Sci U S A 105:15281-15286.

Licatalosi DD, Darnell RB (2006) Splicing regulation in neurologic disease. Neuron 52:93-101.

Lipscombe D (2005) Neuronal proteins custom designed by alternative splicing. Curr Opin Neurobiol 15:358-363.

Martin KC, Kosik KS (2002) Synaptic tagging: who's it? Nat Rev Neurosci 3:813-820.

McBride SM, Giuliani G, Choi C, Krause P, Correale D, Watson K, Baker G, Siwicki KK (1999) Mushroom body ablation impairs short-term memory and long-term memory of courtship conditioning in Drosophila melanogaster. Neuron 24:967-977.

McBride SM, Choi CH, Wang Y, Liebelt D, Braunstein E, Ferreiro D, Sehgal A, Siwicki KK, Dockendorff TC, Nguyen HT, McDonald TV, Jongens TA (2005) Pharmacological rescue of synaptic plasticity, courtship behavior, and mushroom body defects in a Drosophila model of fragile X syndrome. Neuron 45:753-764.

Mehren JE, Ejima A, Griffith LC (2004) Unconventional sex: fresh approaches to courtship learning. Curr Opin Neurobiol 14:745-750.

Menon RP, Gibson TJ, Pastore A (2004) The C terminus of fragile X mental retardation protein interacts with the multi-domain Ran-binding protein in the microtubule-organising centre. J Mol Biol 343:43-53.

Michel CI, Kraft R, Restifo LL (2004) Defective neuronal development in the mushroom bodies of Drosophila fragile X mental retardation $1 \mathrm{mu}-$ tants. J Neurosci 24:5798-5809.

Michelitsch MD, Weissman JS (2000) A census of glutamine/asparaginerich regions: implications for their conserved function and the prediction of novel prions. Proc Natl Acad Sci U S A 97:11910-11915.

Miniaci MC, Kim JH, Puthanveettil SV, Si K, Zhu H, Kandel ER, Bailey CH (2008) Sustained CPEB-dependent local protein synthesis is required to stabilize synaptic growth for persistence of long-term facilitation in Aplysia. Neuron 59:1024-1036.

Monzo K, Papoulas O, Cantin GT, Wang Y, Yates JR 3rd, Sisson JC (2006) Fragile $\mathrm{X}$ mental retardation protein controls trailer hitch expression and cleavage furrow formation in Drosophila embryos. Proc Natl Acad Sci U S A 103:18160-18165.

Morales J, Hiesinger PR, Schroeder AJ, Kume K, Verstreken P, Jackson FR, Nelson DL, Hassan BA (2002) Drosophila fragile X protein, DFXR, regulates neuronal morphology and function in the brain. Neuron 34:961-972.

Mu Y, Otsuka T, Horton AC, Scott DB, Ehlers MD (2003) Activitydependent mRNA splicing controls ER export and synaptic delivery of NMDA receptors. Neuron 40:581-594.

Narayanan U, Nalavadi V, Nakamoto M, Pallas DC, Ceman S, Bassell GJ, Warren ST (2007) FMRP phosphorylation reveals an immediate-early signaling pathway triggered by group $1 \mathrm{mGluR}$ and mediated by PP2A. J Neurosci 27:14349-14357.

Pan Q, Shai O, Lee LJ, Frey BJ, Blencowe BJ (2008) Deep surveying of alternative splicing complexity in the human transcriptome by high-throughput sequencing. Nat Genet 40:1413-1415.

Perutz MF, Johnson T, Suzuki M, Finch JT (1994) Glutamine repeats as polar zippers: their possible role in inherited neurodegenerative diseases. Proc Natl Acad Sci U S A 91:5355-5358.

Pfeiffer BE, Huber KM (2007) Fragile X mental retardation protein induces synapse loss through acute postsynaptic translational regulation. J Neurosci 27:3120-3130.

Richter JD (2007) CPEB: a life in translation. Trends Biochem Sci $32: 279-285$. 
Schena M, Yamamoto KR (1988) Mammalian glucocorticoid receptor derivatives enhance transcription in yeast. Science 241:965-967.

Schenck A, Bardoni B, Moro A, Bagni C, Mandel JL (2001) A highly conserved protein family interacting with the fragile $\mathrm{X}$ mental retardation protein (FMRP) and displaying selective interactions with FMRP-related proteins FXR1P and FXR2P. Proc Natl Acad Sci U S A 98:8844-8849.

Shewmaker F, Mull L, Nakayashiki T, Masison DC, Wickner RB (2007) Ure2p function is enhanced by its prion domain in Saccharomyces cerevisiae. Genetics 176:1557-1565.

Shorter J, Lindquist S (2005) Prions as adaptive conduits of memory and inheritance. Nat Rev Genet 6:435-450.

Si K, Lindquist S, Kandel ER (2003) A neuronal isoform of the Aplysia CPEB has prion-like properties. Cell 115:879-891.

Si K, Choi YB, White-Grindley E, Majumdar A, Kandel ER (2010) Aplysia $\mathrm{CPEB}$ can form prion-like multimers in sensory neurons that contribute to long-term facilitation. Cell 140:421-435.

Siegel RW, Hall JC (1979) Conditioned responses in courtship behavior of normal and mutant Drosophila. Proc Natl Acad Sci U S A 76:3430-3434.

Siomi MC, Siomi H, Sauer WH, Srinivasan S, Nussbaum RL, Dreyfuss G (1995) FXR1, an autosomal homolog of the fragile X mental retardation gene. EMBO J 14:2401-2408.

Sittler A, Devys D, Weber C, Mandel JL (1996) Alternative splicing of exon 14 determines nuclear or cytoplasmic localisation of $\mathrm{fmrl}$ protein isoforms. Hum Mol Genet 5:95-102.

Sondheimer N, Lindquist S (2000) Rnq1: an epigenetic modifier of protein function in yeast. Mol Cell 5:163-172.

Theis M, Si K, Kandel ER (2003) Two previously undescribed members of the mouse CPEB family of genes and their inducible expression in the principal cell layers of the hippocampus. Proc Natl Acad Sci U S A 100:9602-9607.

Van't Padje S, Chaudhry B, Severijnen LA, van der Linde HC, Mientjes EJ, Oostra BA, Willemsen R (2009) Reduction in fragile X related 1 protein causes cardiomyopathy and muscular dystrophy in zebrafish. J Exp Biol 212:2564-2570.

Verkerk AJ, de Graaff E, De Boulle K, Eichler EE, Konecki DS, Reyniers E, Manca A, Poustka A, Willems PJ, Nelson DL (1993) Alternative splicing in the fragile X gene FMR1. Hum Mol Genet 2:399-404.

Wan L, Dockendorff TC, Jongens TA, Dreyfuss G (2000) Characterization of dFMR1, a Drosophila homolog of the fragile $\mathrm{X}$ mental retardation protein. Mol Cell Biol 20:8536-8547.

Weiler IJ, Irwin SA, Klintsova AY, Spencer CM, Brazelton AD, Miyashiro K, Comery TA, Patel B, Eberwine J, Greenough WT (1997) Fragile X mental retardation protein is translated near synapses in response to neurotransmitter activation. Proc Natl Acad Sci U S A 94:5395-5400.

Wickner RB, Edskes HK, Shewmaker F, Nakayashiki T (2007) Prions of fungi: inherited structures and biological roles. Nat Rev Microbiol 5:611-618.

Xie W, Dolzhanskaya N, LaFauci G, Dobkin C, Denman RB (2009) Tissue and developmental regulation of fragile $\mathrm{X}$ mental retardation 1 exon 12 and 15 isoforms. Neurobiol Dis 35:52-62.

Zhang J, Fang Z, Jud C, Vansteensel MJ, Kaasik K, Lee CC, Albrecht U, Tamanini F, Meijer JH, Oostra BA, Nelson DL (2008) Fragile X-related proteins regulate mammalian circadian behavioral rhythms. Am J Hum Genet 83:43-52.

Zhang J, Hou L, Klann E, Nelson DL (2009) Altered hippocampal synaptic plasticity in the FMR1 gene family knockout mouse models. J Neurophysiol 101:2572-2580.

Zhang Y, O'Connor JP, Siomi MC, Srinivasan S, Dutra A, Nussbaum RL, Dreyfuss G (1995) The fragile X mental retardation syndrome protein interacts with novel homologs FXR1 and FXR2. EMBO J 14:5358-5366.

Zhang YQ, Bailey AM, Matthies HJ, Renden RB, Smith MA, Speese SD, Rubin GM, Broadie K (2001) Drosophila fragile X-related gene regulates the MAP1B homolog futsch to control synaptic structure and function. Cell 107:591-603. 